\title{
UM RECORTE DA VARIAÇÃO LEXICAL NO PROJETO ATLAS LINGUÍSTICO DO PARÁ
}

\author{
Abdelhak Razky* \\ Regis José da Cunha Guedes*
}

Resumo: O presente estudo tenta dar conta da variação lexical na zona rural da Mesorregião Metropolitana de Belém (MMB), com base no banco de dados do projeto Atlas Geossociolinguístico do Pará (ALiPA). Os pressupostos teórico-metodológicos da dialetologia, da geografia linguística e da sociolinguística orientam a análise dos dados lexicais. A pesquisa de campo previu a aplicação de um questionário semântico-lexical (QSL), composto de quatorze campos semânticos presentes na realidade sociolinguística de informantes das localidades selecionadas. A amostra total é composta por dezesseis informantes distribuídos geograficamente e socialmente. Os resultados apresentados em cartas linguísticas demonstram o perfil da variação lexical das localidades investigadas, permitindo traçar comparações entre as mesmas.

Palavras-Chave: Variação lexical; atlas linguístico; geolinguística.

Abstract: The present study attempts to account for lexical variation in the rural Metropolitan region of Belém-PA. The study is based on the database of the project Geo-sociolinguistic Atlas of Pará (AliPA) and follows the theoretical and methodological assumptions of dialectology, geolinguistics and sociolinguistics. The field work consists of a lexical-semantic questionnaire (QSL) composed of fourteen semantic fields representing the sociolinguistic reality of informants of the region under study. The total sample consists of sixteen informants distributed geographically and socially. The

* Universidade Federal do Pará. 
results presented in charts demonstrate the linguistic profile of the lexical variation of the localities investigated, allowing to draw comparisons between them.

Keywords: Lexical variation; linguistic atlas; geolinguistics.

\section{Introdução}

Diversos estudos sobre variação geolinguística na língua portuguesa foram realizados nos últimos anos de norte a sul do Brasil, em especial a partir de 1996 com a criação do Comitê Nacional do Atlas Linguístico do Brasil - ALiB. Os projetos de atlas estaduais ou regionais, como o projeto Atlas Geossociolinguístico do Pará - ALIPA, ganharam novo impulso e continuam representando avanços consideráveis nos estudos sobre o português brasileiro, uma vez que registram a língua in vivo, desde os grandes centros urbanos às zonas rurais mais remotas do país. Isso é muito positivo, sobretudo do ponto de vista do registro da diversidade linguística em nosso país.

O presente trabalho se enquadra entre os da dialetologia pluridimensional, que lança mão dos pressupostos teóricometodológicos da sociolinguística para projetar uma imagem multidimensional da variação na língua, em outras palavras, uma imagem que não se restringe meramente ao aspecto espacial ou geográfico, mas que leva em consideração as variáveis sociais no registro da diversidade lexical.

Vale ressaltar a urgência que há no registro dessa diversidade lexical do português, em especial dos falares das zonas rurais. Sobre isso, Couto (2009, p. 146) alerta:

Ao lamentar o desaparecimento dos dialetos rurais, não estou propugnando por um iletramento, um não-acesso ao $\mathrm{DE}$ [dialeto estatal]. Pelo contrário, estou lamentando a perda de todo um conhecimento que se vai com o desaparecimento de uma variante do português. Isso porque, quando uma palavra desaparece, o fato se dá porque a coisa designada por esta também desapareceu ou, pelo menos, o conhecimento que 
a comunidade tinha da coisa, como sabiam os membros da escola dialetológica Wörter und Sachen (palavras e coisas). $\mathrm{O}$ que estou defendendo é a variedade, a diversidade de dialetos, inclusive o dialeto estatal. Como nos ensina a natureza, diversidade representa riqueza, no caso riqueza de meios expressivos, o que não é algo ruim que deve ser extirpado, como querem os normativistas para as variedades não padrão, não estatais.

No intento de registrar a diversidade lexical do português falado na zona rural do estado do Pará, já foram realizados alguns estudos sobre a variação lexical que mapearam dados do ALIPA, ${ }^{1}$ atrelados ao projeto GeoLinTerm. ${ }^{2}$

\section{Os atlas linguísticos: produtos mono, bi ou multidi- mensionais}

Georg Wenker, na Alemanha, e Jules Gilliéron, na França, iniciaram a história dos atlas linguísticos. A publicação do Atlas Linguistique de la France (ALF) (1902-1910) suscitou grande interesse e deu partida a uma série de pesquisas que culminaram na elaboração de vários atlas linguísticos na Europa desde o início do século XX até os dias atuais. O processo naturalmente repercutiu em outras partes do mundo: na América podemos exemplificá-lo com o Atlas Linguístico Diatópico e Diastrático do Uruguai (THUN, FORTE E ELIZAINCÍ́N, 1983), o Atlas Linguístico-Etnográfico do Norte do Chile, ${ }^{3}$ e outros, dentre os quais destacamos o Atlas Linguístico do Brasil - ALiB, que está na eminência da publicação de seu primeiro volume.

\footnotetext{
${ }^{1}$ Martins (2004), Costa (2005), Feitosa (2006), Guedes (2007, 2012) e Gomes (2013).

${ }^{2}$ Geossociolinguística e Socioterminologia: projeto desenvolvido na UFPA, sob a coordenação do professor Abdelhak Razky (concordância), com estudos variacionistas em diversos estados (Pará, Amapá, Amazonas, Rondônia e Acre). ${ }^{3}$ Projeto sob a coordenação de Ángel Araya Peña, na Universidad del Norte no Chile.
} 
A dialetologia tradicional estava ocupada da distribuição geográfica dos dialetos: uma das atividades mais clássicas era a proposição de isoglossas (linhas imaginárias) que delimitam dialetos ou falares próprios de uma determinada região. Os primeiros atlas linguísticos publicados traziam em sua metodologia esta preocupação com a dimensão geográfica, apesar de, segundo Cardoso (2001), em alguns deles como no ALF, ser possível depreender as variantes sociais a partir do exame do perfil dos informantes. Esses atlas, portanto, apresentam uma visão monodimensional da variação linguística.

Thun apud Altino $(2007$, p. 31) propõe uma classificação dos atlas linguísticos em monodimensionais, bidimensionais e pluridimensionais. Para ele, os atlas monodimensionais estão focados na dimensão espacial, por isso permitem a identificação do uso da língua dentro de uma determinada área geográfica. Os atlas bidimensionais, por outro lado, além da dimensão geográfica, contemplam outra dimensão: diagenérica ou diageracional, normalmente. Já os atlas pluridimensionais focalizam, além da dimensão geográfica, duas ou mais dimensões sociais: diastrática, diageracional, diagenérica, diafásica, etc.

Algumas pesquisas adotam a nomenclatura multidimensional para se referir à classificação pluridimensional proposta por Thun (1996, 1997). Para Razky, Oliveira e Lima (2006, p. 117) "um atlas linguístico fornece uma imagem multidimensional, ele mostra onde e como se dão as variações no espaço físico e social". Nessa perspectiva, os atlas linguísticos multidimensionais, inspirados, portanto, nos avançados estudos sociolinguísticos, mapeiam outras variantes além da diatópica (geográfica), como diagenérica ou diassexual (sexo), diageracional (idade), diastrática (classe social), diafásica (escolaridade), somente para citar as mais comuns.

Para Thun apud Altino (2007, p. 31) já no Atlas Linguístico-etnográfico da Itália e da Suíça Meridional - AIS (192840) se pode observar a dimensão diastrática, pois ele "proporciona, para alguns pontos urbanos, os resultados dos famosos 'relevés doublés' [dados binários] feitos em duas camadas citadinas 
diferentes". Por conta disso, pode-se dizer que esse foi o primeiro atlas pluridimensional publicado.

Analisando as metodologias empregadas na produção de sete atlas estaduais e um regional do Brasil, Altino (2007, p. 31), propõe a seguinte classificação:

a) Atlas monodimensionais

Para a autora, os seguintes atlas são classificados como monodimensionais, uma vez que fixaram o interesse de cartografação apenas na dimensão diatópica: o pioneiro Atlas Prévio dos Falares Baianos - APFB (ROSSI, 1963), o Esboço de um Atlas Linguístico de Minas Gerais - EALMG (ZAGARI et al., 1977), o Atlas Linguístico da Paraíba - ALPB (ARAGÃO E MENEZES, 1984) e o Atlas Linguístico-etnográfico da Região Sul do BrasilALERS (KOCH, KLASSMAN E ALTENHOFEN, 2002).

b) Atlas bidimensionais

Como bidimensionais, Altino (2007, p. 42-43) cita os seguintes atlas: Atlas Linguístico de Sergipe - ALS I (FERREIRA ET AL. 1987); Atlas Linguístico de Sergipe - ALS II (CARDOSO, 2002) e Atlas Linguístico do Paraná - ALPR (AGUILERA, 1994), uma vez que os mesmos contemplaram além da dimensão diatópica, a dimensão diagenérica. A essa lista dos atlas bidimensionais acrescentamos o trabalho dela própria, o Atlas Linguístico do Paraná II-ALPR II (ALTINO, 2007), publicado como tese de doutoramento.

c) Atlas pluridimensionais ou multidimensionais

Em sua proposta de classificação, Altino (2007, p. 49) aponta o Atlas Linguístico Sonoro do Pará - ALiSPA (RAZKY, 2004) como o primeiro dos atlas brasileiros com cunho pluridimen-sional, uma vez que estes "combinam a dialetologia areal com a sociolinguística (e a pragmática) para converter o estudo tradicional da superfície bidimensional em um estudo tridimensional da variação linguística" (THUN, 1997, p. 4 apud ALTINO, 2007, p.49). Além desse, a autora cita o Atlas Linguístico do Amazonas - ALAM (CRUZ, 2004) como 
uma tese de doutorado com todas as prerrogativas para ser classificada como um estudo pluridimensional. Ambos (ALiSPA e ALAM) tratam das variantes: diatópica, diagenérica, diageracional e diafásica.

Posteriormente ou concomitantemente à produção da tese de Altino (2007) foram publicados os seguintes atlas: Atlas Linguístico do Mato Grasso do Sul-ALMS (OLIVEIRA, 2007) e o Atlas Linguístico do Ceará-ALECE (BESSA, 2010), além de outros estudos em forma de teses de doutoramento: Atlas Semântico-Lexical da Região do Grande ABC (CRISTIANINI, 2007); Atlas Geolinguístico do Litoral Potiguar-ALiPTG (PEREIRA, 2007) e o Atlas Semântico-Lexical de Caraguatatuba, Ilbabela, São Sebastião e Ubatuba (ENCARNAÇÃO, 2010). Todos esses estão enquadrados como produtos pluridimensionais ou multidimensionais, por atenderem aos critérios estabelecidos por Thun (1996, 1997). Também devem ser inseridos nesse elenco outros atlas que estão em fase de elaboração atualmente, dentre eles destacamos o Atlas Linguístico do Brasil-ALiB e o Atlas Geossociolinguístico do Pará-ALIPA.

\section{Instrumentos e métodos da pesquisa}

Investiga-se no presente trabalho a variação lexical da Mesorregião Metropolitana de Belém (MMB). Um recorte no corpus do projeto Atlas Geossociolinguístico do Pará (ALiPA) permitiu a seleção de dezesseis informantes pertencentes a quatro municípios da MMB: Bujaru, Castanhal, Santa Isabel do Pará e Santo Antônio do Tauá. Seguindo o modelo da dialetologia pluridimensional, foram mapeadas a variação diatópica (espacial), diagenérica (sexo) e diageracional (faixa etária).

A seleção dos informantes seguiu os critérios do projeto ALIPA: escolaridade igual ou inferior à $4^{\mathrm{a}}$ série do ensino fundamental; um do sexo masculino e um do sexo feminino, entre 18 e 30 anos e um do sexo masculino e um do sexo feminino, entre 40 e 70 anos, para cada uma das localidades. 
Os informantes foram submetidos a um Questionário Semântico-lexical (QSL) composto por 257 questões, sendo 256 perguntas e uma solicitação para que o informante faça um relato de experiência pessoal. As perguntas estão distribuídas em 14 campos semânticos, quais sejam: natureza e acidentes geográficos; fenômenos atmosféricos; astros e tempo; flora; atividades agropastoris; fauna; corpo humano; cultura e convivio; ciclos da vida; religiões e crenças; festas e divertimentos; habitação; alimentação e cozinha; e vestuário.

\section{Apresentação e discussão dos resultados}

Para nortear a leitura das cartas apresentadas, foi elaborada uma carta explicativa (figura 1).

A lexia lago foi a mais recorrente, com cinco registros, obtidos nas quatro localidades pesquisadas.

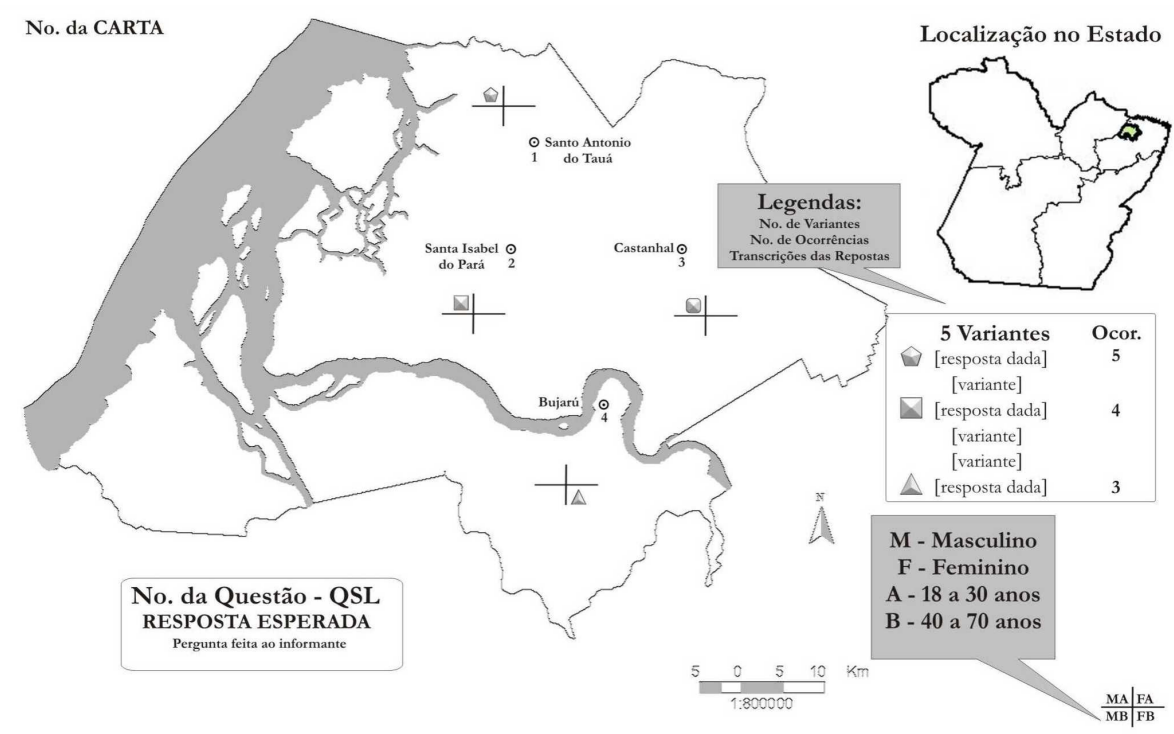

FIGURA 1: Carta Explicativa para a MMB 
A carta 02 (fig. 2) a seguir, referente à questão 13 do QSL, apresentou um total de cinco variantes lexicais.

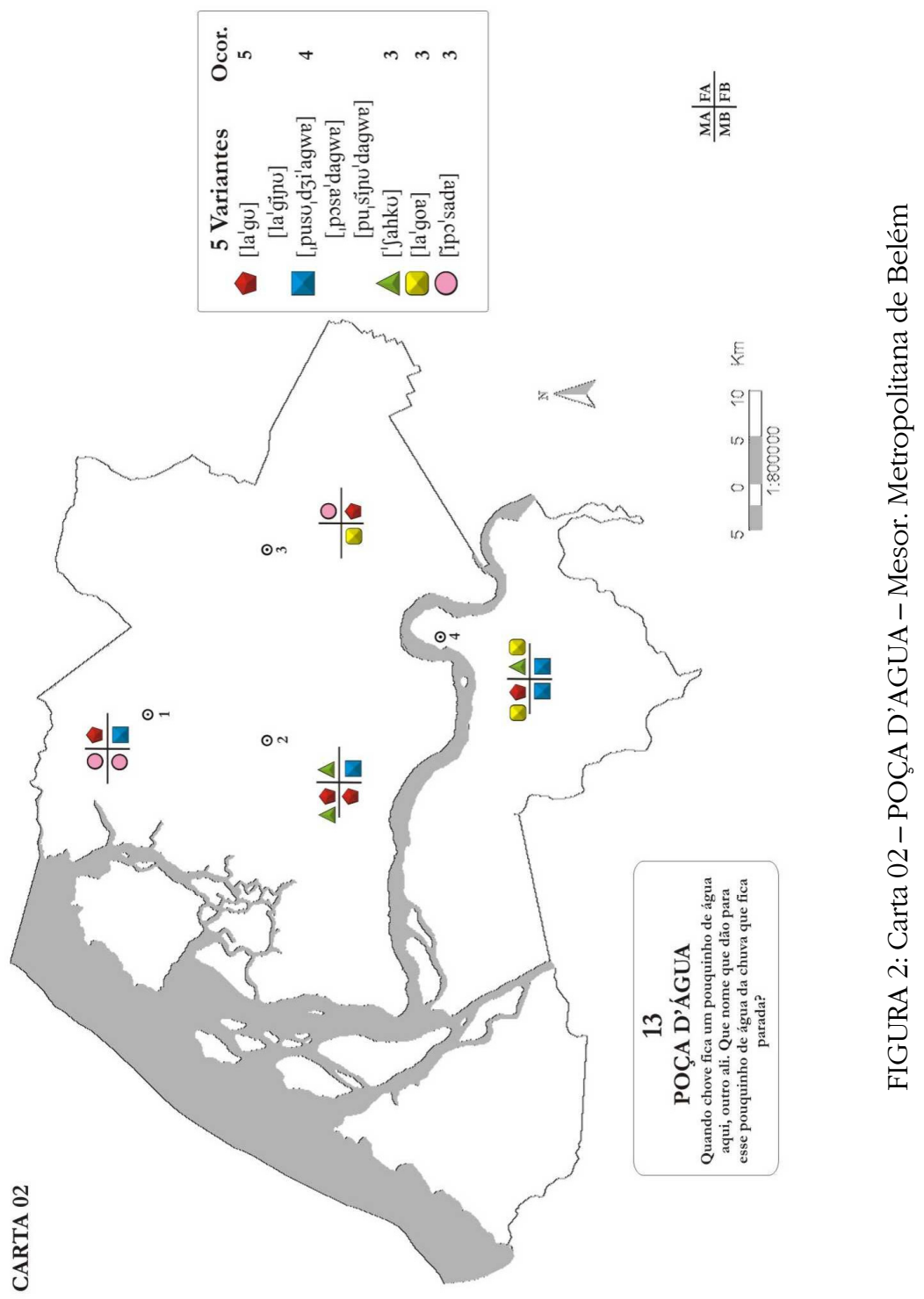


A lexia lago foi a mais recorrente, com cinco registros, obtidos nas quatro localidades pesquisadas.

A lexia charco, registrada nos municípios de Santa Isabel do Pará (ponto 2) e Bujaru (ponto 4), é dicionarizada por Ferreira (2009) como água estagnada e imunda de pouca profundidade. Do ponto de vista da variação diageracional, observou-se que o registro dessa lexia se deu somente na fala dos informantes da primeira faixa etária. A variante poça d'agua se destaca apenas nas respostas dos informantes de segunda faixa etária. Das 4 ocorrências dessa variante, 3 foram obtidas de informantes de sexo feminino.

A carta 11 (fig. 3) a seguir, referente à questão 64 do QSL, é uma das mais produtivas desta pesquisa, apresentando sete variantes lexicais. Nela foi cartografada a lexia incunba, variante de inconha, na fala de MB de Santo Antônio do Tauá (ponto 1). Segundo Ferreira (2009), essa lexia é de origem tupi, e designa um "fruto que nasce pregado a outro".

Controlando-se a distribuição diageracional, o fato de a lexia incunba ter sido registrada somente por um informante da segunda faixa etária pode indicar que a mesma está caindo em desuso no português falado no estado do Pará, hipótese esta reforçada por Costa (2005, p. 46), que mapeou a variação lexical em quatro municípios do nordeste paraense. ${ }^{4}$ Como se pode ver na carta lexical abaixo (fig. 4), as variantes de inconba foram registradas somente na fala de informantes da segunda faixa etária (MB e FB) do município de Viseu (ponto 4), no extremo nordeste do estado.

${ }^{4}$ Quais sejam: 1. Abaetetuba; 2. Maracanã; 3. Moju e 4. Viseu. 


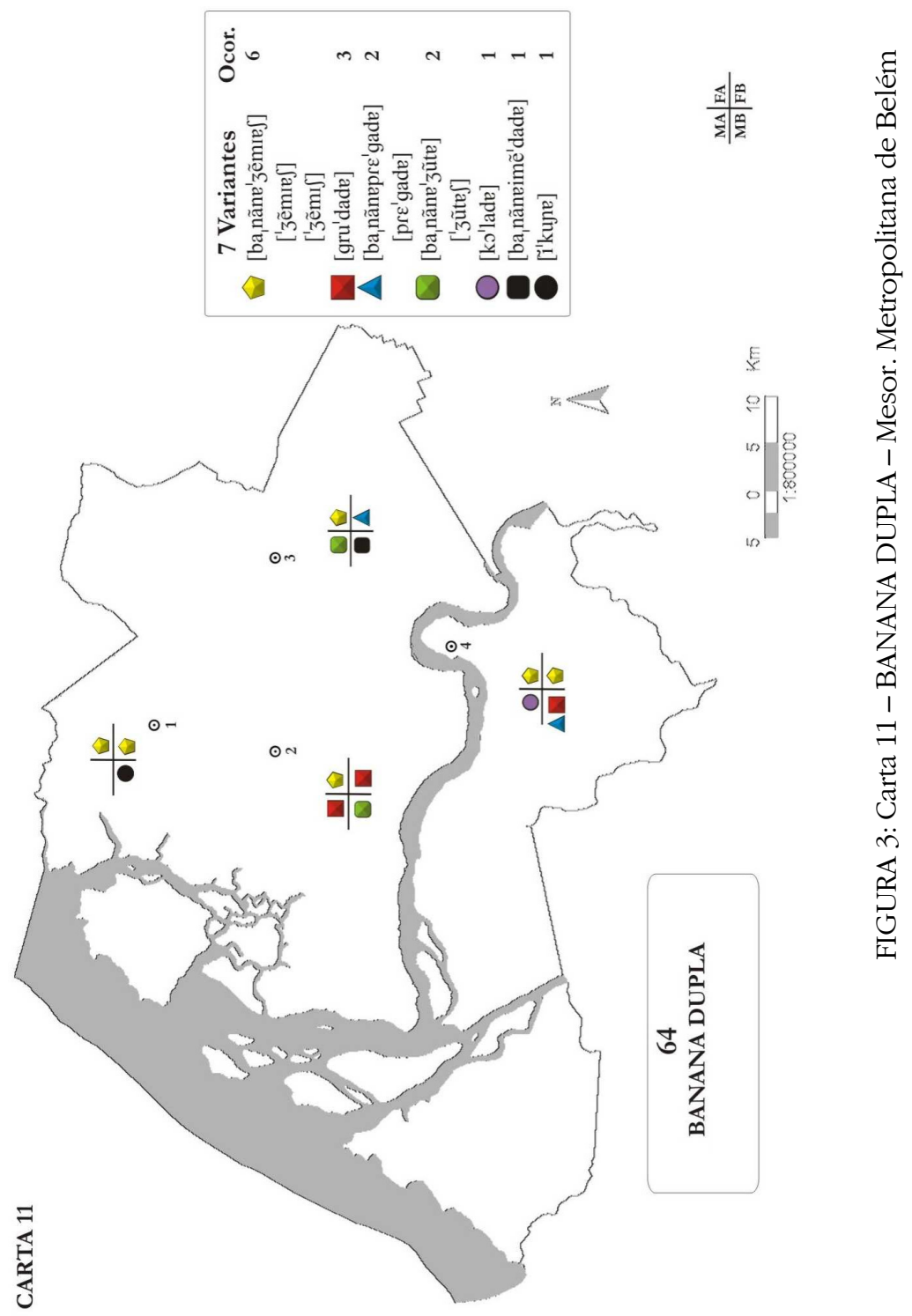




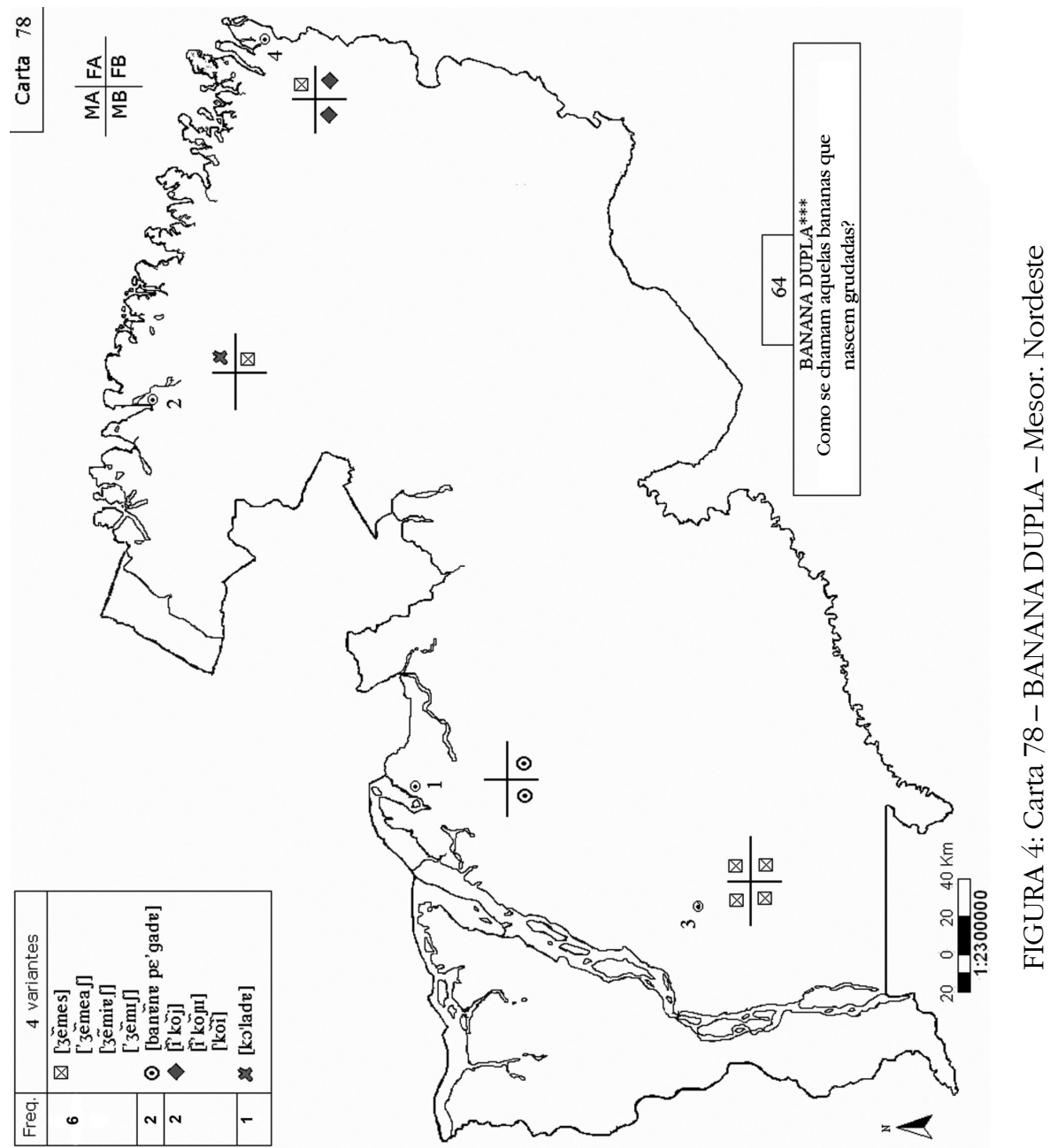


Outro aspecto que chama a atenção diz respeito à variação diagenérica da variante bananas gêmeas, que aponta uma predominância na fala dos informantes do sexo feminino. $O$ mesmo resultado foi registrado em Costa $(2005$, p. 46), onde essa variante foi registrada em três municípios (pontos $2,3 \mathrm{e} 4$ ) para $\mathrm{o}$ sexo feminino e somente em um para o masculino, como se pode observar no mapa acima. Essa tendência de predominância da lexia em questão para o sexo feminino também foi constatada em um mapeamento do léxico da cidade de Adrianápolis (PR), realizado por Altino e citado por Rodrigues (2007, p. 144). Nessa pesquisa a lexia bananas gêmeas foi registrada com $70 \%$ das ocorrências para as mulheres, e com $30 \%$ para os homens.

O estudo de Altino (2007) também indica uma porcentagem de $60,3 \%$ de ocorrências para o sexo masculino da lexia inconha. Nas duas mesorregiões paraenses em questão (metropolitana e nordeste), obtiveram-se dados similares, uma vez que se tem o registro dessa lexia para dois homens e uma mulher, o que incita uma investigação mais abrangente, no intuito de confirmar essas tendências, bem como de desvendar as motivações sociais e/ou linguísticas para as mesmas.

A carta 15 (fig. 5) a seguir, elaborada a partir das respostas para a questão 102 do QSL, apresentou quatro variantes lexicais no total, a lexia arapuca foi a mais recorrente (8 ocorrências), tendo sido registrada nos quatro pontos de inquéritos investigados. Em relação à distribuição diagenérica e diageracional dessa lexia, verificou-se que há predominância de ocorrências dela para a primeira faixa etária (75\%) em relação à segunda (25\%), e para o sexo masculino $(62,5 \%)$ em relação ao feminino $(37,5 \%)$. 


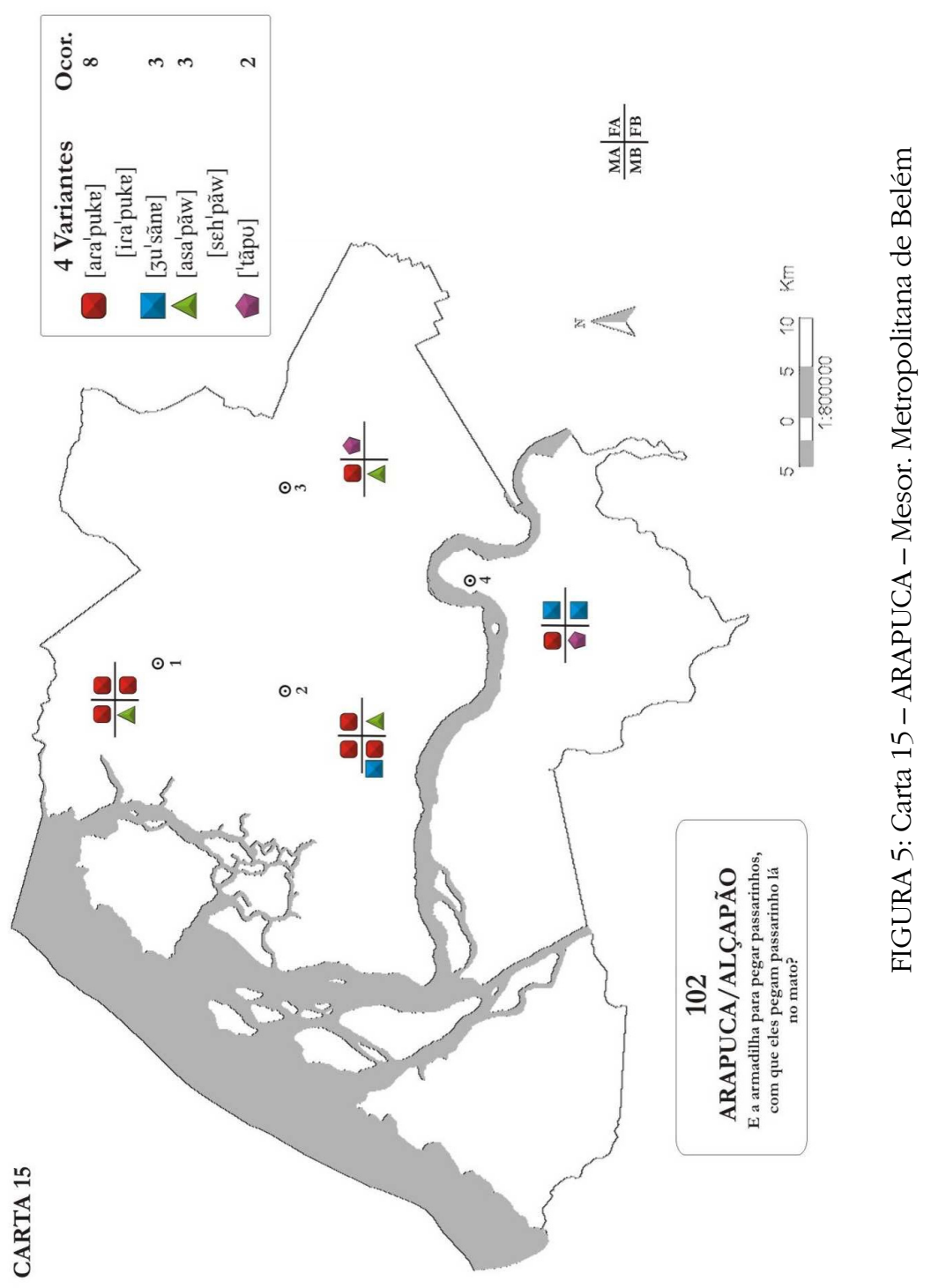


A carta 15 (fig. 5) mostra que a lexia juçâna foi registrada na fala dos informantes FB de Santa Isabel (ponto 2), MA e MB de Bujaru (ponto 4). Ferreira (1999, p. 1165) registra essa lexia exatamente nesta acepção: "[Do tupi.] S. f. Bras. Armadilha ou laço para apanhar passarinhos".

Controlando-se a variante diatópica na carta 30 (fig. 6) a seguir, referente à questão 229 do QSL, observa-se que, na Mesorregião Metropolitana de Belém, somente no município de Santo Antônio do Tauá houve o registro da lexia tisna, ocorrida na fala de três dos quatro informantes. Ferreira (2009) registra essa lexia como "substância preparada para enegrecer qualquer coisa", derivada do verbo tisnar (do latim vulgar titionare), que está relacionado a tição, carvão. Esse autor registra também a variante tisne na acepção de "cor que o fogo ou fumaça produzem na pele".

Observando-se a distribuição diagenérica e diatópica da lexia taticumã (fig. 6), pode-se verificar a predominância da mesma para o sexo feminino (80\%) em detrimento do sexo masculino (20\%), da mesma forma há predominância dessa lexia para a segunda faixa etária (60\%) em relação à primeira (40\%). Assim, a carta mostra que o falante típico de taticumã na zona rural da $\mathrm{MMB}$, em sua maioria, é mulher pertencente à segunda faixa etária (40 a 70 anos). 


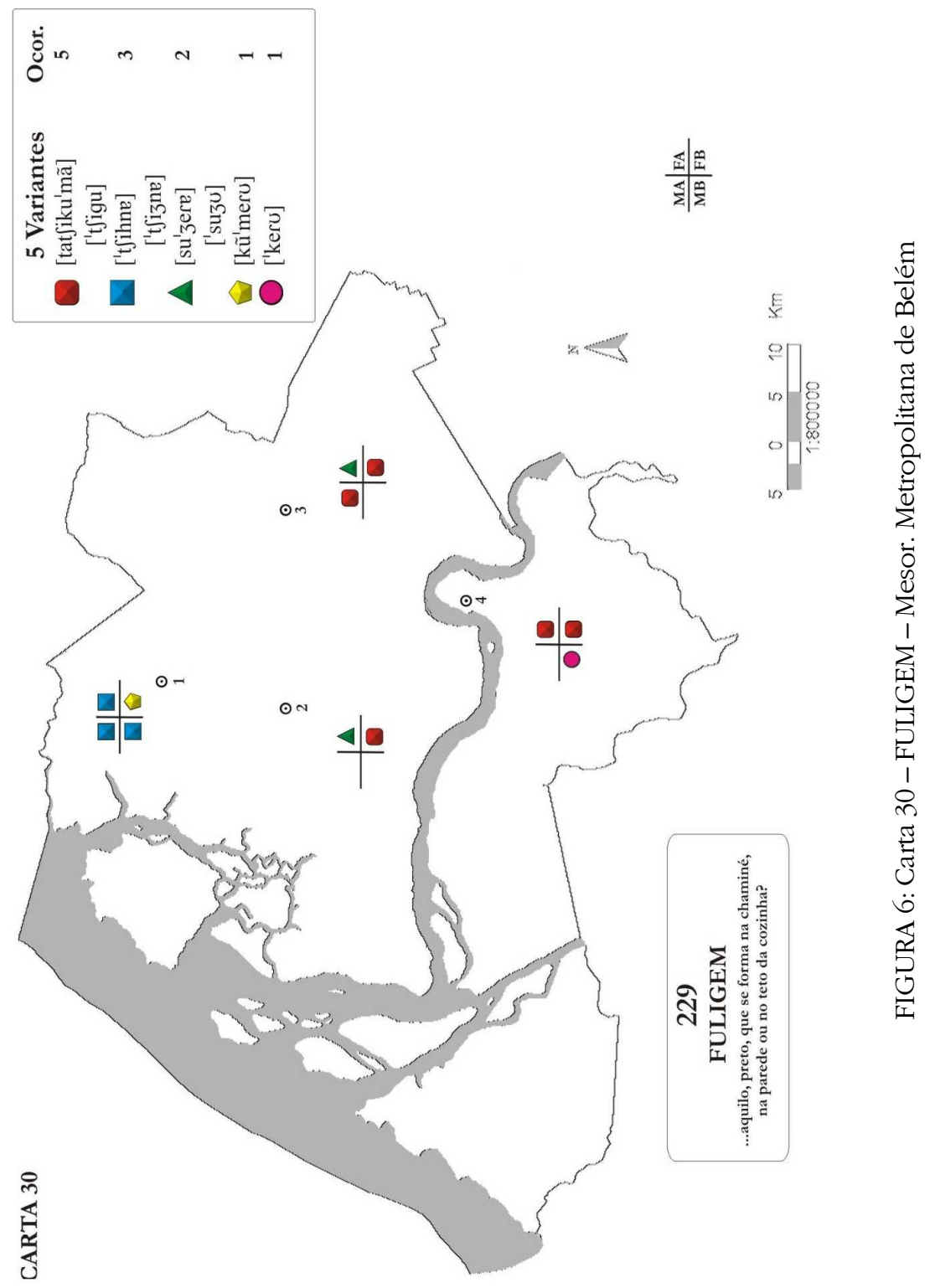




\section{Considerações finais}

O mapeamento da variação lexical na zona rural da Mesorregião Metropolitana de Belém - MMB demonstrou a produtividade lexical no espaço diatópico estudado. As figuras $3 \mathrm{e}$ 4 (bananas gêmeas) ilustram bem essa riqueza. Os resultados demonstram, além da diversidade lexical, uma riqueza cultural no estado do Pará. A partir da análise das cartas 11 (fig. 3), 78 (fig. 4) e 15 (fig. 5), nas quais foram registradas lexias como juçâna, arapuca e incunha, verifica-se que o léxico do português falado no Pará possui significativa influência do léxico de línguas do tronco tupi. Assim, reforça-se a importância dos estudos dialetológicos com fontes confiáveis para o desenvolvimento de estudos sobre a história social das comunidades de falantes.

A visão pluridimensional aponta também para a importância de uma estratificação social de amostras geolinguísticas que permitem corroborar, como mostram as imagens preliminares aqui apresentadas, os conceitos de contínuo e fluxo lexical no espaço rural. Esperam-se resultados mais abrangentes oriundos da zona rural paraense que serão projetados quando da publicação do Atlas Geossociolinguístico do Pará.

\section{Referências}

AGUILERA, V. de A. Atlas linguístico do Paraná. Curitiba: Imprensa Oficial do Estado do Paraná / Londrina: UEL, 1994.

ALTINO, F. C. Atlas linguístico do Paraná II. 2007. Tese (Doutorado) Centro de Letras e Ciências Humanas, Universidade Estadual de Londrina.

ARAGÃO, M. S. da S.; MENEZES, C. B. de. Atlas linguístico da Paraíba. Universidade Federal da Paraíba/CNPq, 1984.

BESSA, J. R. F. (Org.) Atlas linguístico do Ceará. Fortaleza: Ed. da UFC, 2010.

CARDOSO, S. A. M. Dialectologia: trilhas seguidas, caminhos a perseguir. Delta, São Paulo, v. 17, n. esp., p. 25-44, 2001. 
CARDOSO, S. A. M. Atlas linguístico de Sergipe II. 2002. Tese (Doutorado) - Universidade Federal do Rio de Janeiro.

COSTA, C. S. Variação lexical no nordeste do Pará. 2005. Trabalho de Conclusão de Curso (Graduação em Letras) - Instituto de Letras e Comunicação, Universidade Federal do Pará.

COUTO, H. H. do. Linguística, ecologia e ecolinguística: contato de línguas. São Paulo: Contexto, 2009.

CRISTIANINI, A. C. Atlas Semântico Lexical da Região do Grande ABC. 2007. Tese (Doutorado) - Faculdade de Filosofia, Letras e Ciências Humanas, Universidade de São Paulo.

ENCARNAÇÃO, M. R. T. da. Atlas semântico-lexical de Caraguatatuba, Ilbabela, São Sebastião e Ubatuba. 2010. Tese (Doutorado) - Faculdade de Filosofia, Letras e Ciências Humanas, Universidade de São Paulo.

FEITOSA, A. da S. Variação lexical no sudeste do Pará. 2006. Trabalho de Conclusão de Curso (Graduação em Letras) - Instituto de Letras e Comunicação, Universidade Federal do Pará.

FERREIRA, A. B. de H. Novo aurélio século XXI: o dicionário da língua portuguesa. 3. ed. Rio de Janeiro: Nova Fronteira, 1999.

FERREIRA, A. B. de H. Novo dicionário eletrônico aurélio. Curitiba: Positivo, 2009. CD-ROM, versão 6.

FERREIRA, C. et al. Atlas linguístico de Sergipe. Salvador: UFBA/ Fundação Estadual de Cultura de Sergipe, 1987.

GOMES, E. de F. Variação lexical em seis municípios da mesorregião sudeste paraense. 2013. Dissertação (Mestrado em Letras) - Instituto de Letras e Comunicação, Universidade Federal do Pará.

GUEDES, R. J. da C. Variação lexical em quatro municípios da mesorregião metropolitana de Belém. 2007. Trabalho de Conclusão de Curso (Graduação em Letras) - Instituto de Letras e Comunicação, Universidade Federal do Pará.

GUEDES, R. J. da C. Estudo geossociolinguístico da variação lexical na zona rural do Estado do Pará. 2012. Dissertação (Mestrado em Letras) - Instituto de Letras e Comunicação, Universidade Federal do Pará.

KOCH, W.; KLASSMANN, M. S.; ALTENHOFEN, C. V. (Orgs). Atlas linguístico-etnográfico da região sul do Brasil. Porto Alegre/ Florianópolis e Curitiba: UFRGS/UFSC/ UFPR, 2002. 
MARTINS, A. F. C. Variação lexical e fonética na Ilha do Marajó. Revista Científica da UFPA, Belém, v. 4, abr. 2004.

OLIVEIRA, D. P. de (Org.)_ALMS - Atlas linguístico de Mato Grosso do Sul. Campo Grande: Ed. da UFMS, 2007.

PEREIRA, M. das. N. Atlas geolinguístico do litoral potiguar-ALiPTG. 2007. Tese (Doutorado em Letras Vernáculas), Universidade Federal do Rio de Janeiro.

RAZKY, A. (Org.) Atlas linguístico sonoro do Pará. Belém /CAPES/UTM, 2004. CD-ROM.

RAZKY, A; OLIVEIRA, M. B. de; LIMA, A. Contribuições da dialetologia para o ensino. In: MOTA, J. A.; CARDOSO, S. A. M. Documento 2: projeto atlas linguístico do Brasil. São Paulo: Quarteto, 2006.

RODRIGUES, R. E. de S. B. Em busca de uma história social para o léxico rural paranaense. 2007. Tese (Doutorado) - Centro de Letras e Ciências Humanas, Universidade Estadual de Londrina.

ROSSI, N. Atlas prévio dos falares baianos. Rio de Janeiro: Instituto Nacional do Livro/Ministério da Educação e Cultura, 1963.

THUN, H.; FORTE, C.; ELIZAINCÍN, A. El Atlas linguístico diatópico y diastrático del Uruguay (ADDU): presentación de un proyecto. Iberoromania, Berlin, v. 30, p. 28-62, 1983.

THUN, H. Movilidad demográfica y dimensión topodinâmica. Los montevideanos em Rivera. In: THUN, H.; RADTKE, E. Neue Wege der romanischen Geolinguistik: Akten des Symposiums zur empirischen Dialektologie (Heidelberg/Mainz 21-24.10.1991). Kiel: Westensee, 1996. p. 210-225.

THUN, H. A dialetologia pluridimensional no Rio do Prata. Porto Alegre: UFRGS, 1997.

ZÁGARI, M. R.L. et al. Esboço de um Atlas Linguístico de Minas Gerais.Rio de Janeiro: Ministério da Educação e Cultura/Fundação Casa de Rui Barbosa, Universidade Federal de Juiz de Fora, 1977.

Recebido para publicação em 10 de junho de 2013 Aprovado em 25 de setembro de 2013 